九州大学学術情報リポジトリ

Kyushu University Institutional Repository

\title{
Heating Characterization of Low Energy Consumption Lab-on-a-Chip
}

Irwansyah, Ridho

Department of Mechanical Engineering, Faculty of Engineering Universitas Indonesia

Juana, Felix

Department of Mechanical Engineering, Faculty of Engineering Universitas Indonesia

Whulanza, Yudan

Department of Mechanical Engineering, Faculty of Engineering Universitas Indonesia

Charmet, Jerome

Institute of Digital Healthcare, University of Warwick

https://doi.org/10.5109/4742135

出版情報：Evergreen. 8 (4)，pp.872-878，2021-12. 九州大学グリーンテクノロジー研究教育センター バージョン：

権利関係 : 


\title{
Heating Characterization of Low Energy Consumption Lab- on-a-Chip
}

\author{
Ridho Irwansyah $^{1}$, Felix Juana ${ }^{1}$, Yudan Whulanza ${ }^{1,2, *}$, Jerome Charmet ${ }^{3}$ \\ ${ }^{1}$ Department of Mechanical Engineering, Faculty of Engineering Universitas Indonesia, Kampus UI Depok, Indonesia \\ 16424 \\ ${ }^{2}$ Research Center for Biomedical Engineering, Faculty of Engineering, Universitas Indonesia \\ ${ }^{3}$ Institute of Digital Healthcare, University of Warwick
}

*Author to whom correspondence should be addressed:

E-mail: yudan@eng.ui.ac.id

(Received April 30, 2021; Revised December 16, 2021; accepted December 16, 2021).

\begin{abstract}
The ultimate goal of this study is to develop an effective and user-friendly form of thermal cycler to perform Polymerase Chain Reaction (PCR). This paper research the ability to manufacture a thermal cycler using conventional methods and readily available components to achieve a significant performance result with low production cost compared with commercially available counterparts. Commonly, thermal cyclers use an aluminum heating block as a heating vessel for samples, to achieve fast temperature changes and uniformity, but Polydimethylsiloxanes (PDMS) lab-on-a-chip (LoC) is utilized in contrast to silver as a heating vessel in this study to achieve biocompatibility with various samples. The raspberry-Pi pocket computer was used to achieve the necessary control with room for future capabilities addition and improvement. Characterization of the heating and PCR processes was done to understand the heat transfer phenomenon and thermal cycling speed in PDMS environment. This paper also includes analysis of the cycle speed corresponding to the control parameters of the manufactured thermal cycler. Ultimately, the characterization and analysis results will show the achieved performance capabilities of the thermal cycler.
\end{abstract}

Keywords: lab-on-a-chip, polymerase chain reaction, PDMS, thermal cycler.

\section{Introduction}

Polymerase chain reaction (PCR) is commonly used to make copies of a specific DNA segment. Through PCR, a small amount of DNA sample can be exponentially amplified, resulting in thousands to millions of copies. This makes the PCR method become widely used in the medical and clinical laboratory, with varied applications in forensics, biology and medicines ${ }^{1-4)}$.

The heart of the PCR technology is the thermal cycler module that copying the DNA the sample by exposing in 3 specific temperature ranges, which is denaturation (90$\left.95^{\circ} \mathrm{C}\right)$, annealing $\left(60-65^{\circ} \mathrm{C}\right)$, and elongation $\left(70-75^{\circ} \mathrm{C}\right)$. Therefore, one interest in this technology is engineering the thermal process during the amplification ${ }^{5}$. A recent development in microcontroller enables us to realize simple thermal management hence adding the portability of the device ${ }^{6-8)}$. Additionally, the energy management was proven to be handle by batteries to make it more portable $^{9-11)}$. The battery technology provides a more promising energy resource to be used in a long time and more separate area with national grid ${ }^{12,13)}$. Moreover, the portability of PCR has proven to make use of the PCR to be widely used such as in detection of influenza virus ${ }^{14-}$ ${ }^{17)}$. Another research on LoC has also been performed for a biological cells separation ${ }^{18)}$.

A recent development in microfabrication has allowed us to manufacture a lab-on-a-chip (LoC) module to accommodate PCR process in a single microfluidic chi $^{19,20)}$. The LoC provides the filtering, the mixing, liquid handling, and heating of the specimen and reagents ${ }^{21-25)}$. This allows us to decrease the expected consuming time for the process of PCR. Ultimately, we could realize a PCR with a lower sample volume, faster cycle speed, and better yield concentration of the desired DNA copy. Therefore, it has become necessary to develop a thermal cycler that accommodates LoC PCR rather than the conventional PCR that uses metallic heating element ${ }^{26,27)}$.

This research aims to develop a PCR with LoC as a cartridge that not only cheap and easy to built ${ }^{28)}$, but also easy to operate and to maintain using a Raspberry-Pi minicomputer. This minicomputer is used as a central control unit for its faster processing capabilities and its 
traits of user-friendly interface and application. The more rapid processing capabilities of Raspberry- Pi will be the foundation of an optimally designed control system with the extra capabilities that served for further application and improvements of the thermal cycler module.

\section{Methodology}

The thermal cycler is assembled from multiple components to generate a controlled heating system needed for PCR processes. The result is a thermal cycler with an overall dimension of $35 \mathrm{~cm}$ long, $25 \mathrm{~cm}$ wide, and $11 \mathrm{~cm}$ tall. It holds a heating chamber designed to isolate the heating environment during usage with the overall chamber's heating space dimension of $9 \mathrm{~cm}$ long, $9 \mathrm{~cm}$ width, and $2.5 \mathrm{~cm}$ tall. As a prototype, it can accommodate a single PDMS chip which will be heated and cooled through conduction with two Peltier elements during PCR processes. The thermal cycler will generate the three required temperature zones following the user's input of the desired set temperature for the temperature zones and cycle amount. To produce the optimal result of PCR, the PDMS chip used on the process must be shaped to the dimension of at least $75 \mathrm{~mm}$ long, $25 \mathrm{~cm}$ wide, $2 \mathrm{~mm}$ thick on the non-channel segment and 600 microns thick on the channel segment.

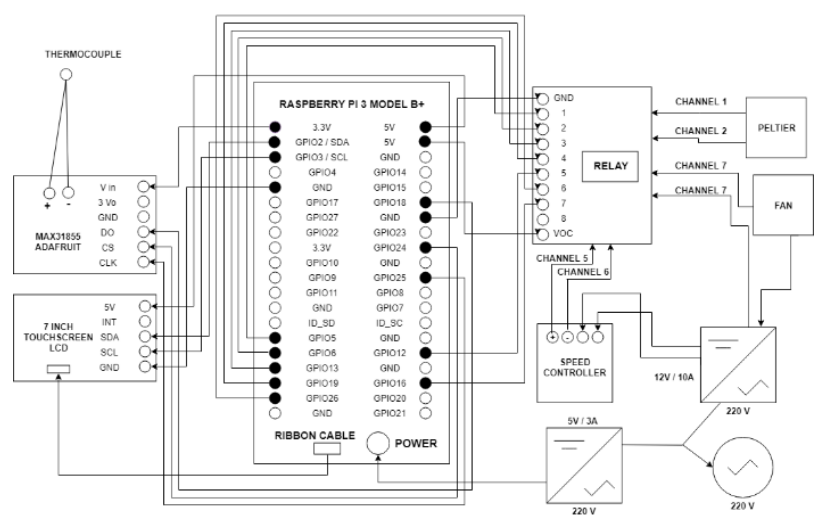

Fig. 1: Schematic design of the thermal cycler electrical component wiring

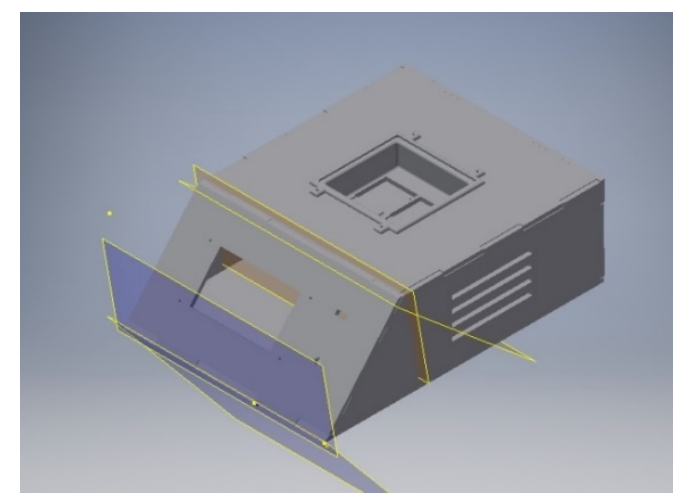

(a)

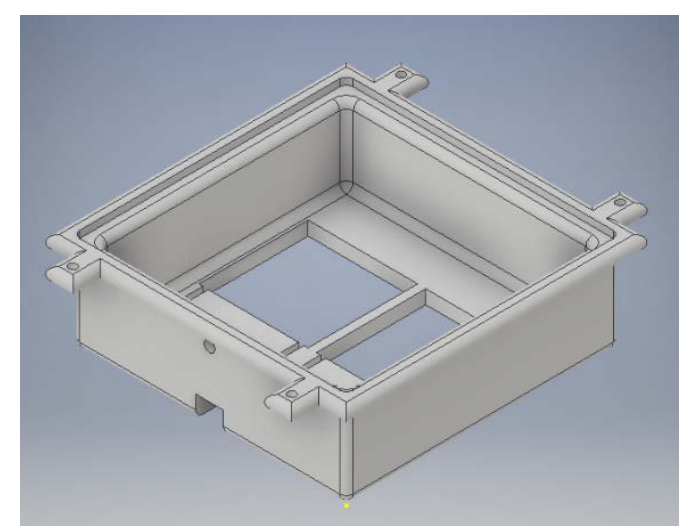

(b)

Fig. 2: Design of the thermal cycler (a) physical model and (b) heating chamber

The prototype usage is initiated by running a program consists of a set of codes that simulates a thermal cycler function on the Raspberry-Pi terminal. The program runs by first inputting the required control parameters, which is the desired cycle amount, denaturation set temperature, annealing set temperature, and elongation set temperature. From the inputted temperature parameters, the program will make a temperature zone for each category to act as a control range of the PCR processes. The thermal cycler then will run and continuously heats and cools the sample to achieve parameter temperatures in a sequence of denaturation, annealing, and elongation as much as the value of the desired cycle amount inputted by the users. The thermal cycler can run indefinitely as long as it is power needs are continuously supplied, but it is advised to run the PCR in a short amount of cycle at a time to avoid damaging the Peltier elements. Should the PCR processes fail mid-process such as failure to cools or heats the sample, the thermal cycler is equipped with a direct command to stop the process where then the user can replace the Peltier that is damaged. The schematic of the electrical wiring and the design of the thermal cycler are depicted in Fig. 1 and Fig. 2, respectively.

The Control system of the thermal cycler runs by using data of PDMS temperature taken by a thermocouple at real-time to produce an accurate control for PCR processes. The result is a thermal cycler prototype designed for flexibility, ease of usage, and precise heating control with little overshoot or undershoots capable of producing acceptable results on uncontrolled free environment parameters. As a result, certain boundary conditions are applied to the prototype to achieve those targets such as:

- The PDMS LoC sample is heated through direct conduction with the Peltier elements. There should be no obstruction in any material between the sample and Peltier elements of ceramic surfaces.

- The PDMS LoC will be heated from the bottom of the chip surface.

- The thermal cycler should be run under the condition 
as close as atmospheric pressure and room temperature.

Table 1. Thermal properties of PDMS Material property

\begin{tabular}{lc}
\hline Density $\left(\mathrm{kg} / \mathrm{m}^{3}\right)$ & 0.97 \\
Specific heat $(\mathrm{J} /(\mathrm{kg} \mathrm{K}))$ & 1,460 \\
Thermal conductivity $(\mathrm{W} /(\mathrm{m} \mathrm{K}))$ & 0.15 \\
\hline
\end{tabular}

The thermal cycler is tested for specifications for acquiring the solid value of the prototype's capabilities which serve as a base foundation to further develop the PCR process control system. With the known parameters of the PDMS and thermal cycler, the heating process can be modeled to show how the conduction heating works. Such are the tables of the PDMS characteristics and final thermal cycler specifications.

Table 2. Thermal cycler prototype specifications

\begin{tabular}{|l|l|}
\hline Dimensions & $\begin{array}{l}250 \text { X } 350 \text { X } 110 \mathrm{~mm}^{3} \\
\text { (W X L X H) }\end{array}$ \\
\hline Power Consumption & $\begin{array}{l}15 \text { Watt (Idle) } \\
70 \text { Watt (Max) }\end{array}$ \\
\hline Sample Capacity & 1 \\
\hline Temperature Range & $10-100^{\circ} \mathrm{C}$ \\
\hline Temperature Accuracy & $\pm 0.25^{\circ} \mathrm{C}$ \\
\hline Temperature Ramp Rate & $1.75 \pm 0.25^{\circ} \mathrm{C}$ \\
\hline
\end{tabular}

From the known PDMS properties, LoC design, and test data, we can model a simple conduction formula in the form of 2 variables linear equation. The boundary variable is the heat flux produced in the conduction phenomenon and the free variable by the temperature difference between the Peltier element and PDMS surfaces. The equation can also be inverted to switch the variable's free and bound status should there be the needs.

The conduction heat transfer formula is known as:

$\frac{\dot{Q}}{A}=k \frac{\Delta T}{d}$

With $\dot{Q}$ is the heat that is transferred through conduction per moment, $A$ is the surface area of the channeled surface of the PDMS LoC in contact with the heating element, $k$ is the material thermal conductivity, $\Delta T$ is the temperature difference between known material, and $d$ is the distance between the point where sample temperature is measured and the heat source.

Combined with known parameters of thermal conductivity of $0.15 \mathrm{~W} /(\mathrm{m} \mathrm{K})$ and distance of 600 microns, the simple model for the PDMS LoC conduction phenomenon can be developed, which is:

$$
\frac{\dot{Q}}{A}=250 \Delta T
$$

This model of the equation can be used in conjunction with the user's design of the chip and real-time temperature data to understand further how the conduction phenomenon will happen on the heating processes.

The thermal cycler heating system is assembled from sets of heating elements, sensors, power supply, and main control systems for data acquisition and close-loop heating control systems. PDMS LoC is placed on the surface of 2 Peltier elements powered by $12 \mathrm{~V} 10$ A power supply with an area of $40 * 40 \mathrm{~mm}^{2}$ each where the entire heating and cooling of the 3 temperature zones take place. The decision is made to use the Peltier element as the heating element based on its working principles of the thermoelectric effect, where it can generate heating and cooling effect by changing the polarity of the direct current that powers the element. This reduces the chances of temperature overshoots and undershoots by another conventional heater, resulting in more accurate and precise heating control. Type-K thermocouple is used as a temperature sensor to monitor the PDMS LoC temperature in real-time, where it can be saved in the data archive, which is also used to be the parameters of the closed-loop heating control system. The main control system real-time data acquisition gives the thermal cycler ability to run a flexible real-time heating control, resulting in accurate and precise control based on the real condition of the heating processes. While the usage of the Raspberry-Pi as a control system also allows saving and back-up the data acquitted in each trial in the remote server should it be connected to the internet, giving it an effective way to archive the data.

As the PCR process is highly dependent on how the temperature control works, it is critical how each temperature zones will be maintained. To achieve that performance, the temperature of the PDMS LoC will be measured and compared to the set value of the temperature inputted by the user. The Upper and lower control limit of the set temperature will be made for each temperature zone by the control logic of the control system. With the required PDMS LoC contact surface is overall smaller than the heating element surface, heating will produce a uniform temperature across the PDMS body, consistent heating for the tested sample can be achieved, resulting in a uniform and reliable PCR process.

From the upper and lower control limit of the temperature zones set temperatures, the control logic can be conducted to produce controlled heating. The logic of the control system runs by continually comparing the realtime measurement of the PDMS temperature to the set temperatures parameter in a series of set temperature values. Should the measurement value is lower than the lower limit of the set temperatures parameter, the relay 
inside will switch on, and the electric current will flow to the Peltier, activating it and heating the PDMS. Then, should the measurement is higher than the upper control limit of the set temperatures parameter, the relay will switch to change from the heating setting of the relay system to the cooling set, where the wiring is reflected to bring a reverse polarity effect, therefore switching the heating and cooling side of the Peltier and effectively cools the PDMS. The goal is to maintain the temperature of the sample between the upper and lower control limit of the set temperature and maintain it for a set value of time to finish the process. Only when set temperature control is achieved will the logic start the process again under different set temperature values. This will run continuously until it has run for the specified amount of cycle inputted by the user.

\section{Result and Discussion}

Measurement of the PCR heating and cooling processes is solely conducted to acquire temperature data in realtime using the type-K thermocouple. The sensor will be in direct contact with the PDMS LoC channel to measure PDMS temperature value through conduction. Data will be acquired in the form of temperature value for 2 seconds interval. As the PDMS LoC is heated in its entirety, assumption of temperature uniformity in the PDMS LoC body is taken to counteract the Raspberry-Pi inability to host several sensors at once, eliminating the chance to conduct a multipoint measurement.

With the usage of the sensor, it becomes necessary to calibrate the sensor to produce data truly representing the phenomenon that happens. Calibration is done by measuring the Peltier element on the same spot using both a Fluke 59 Max standardized infrared thermometer as calibrator and the type-K thermocouple. The measurement will be done from the range of room temperature to 100 ${ }^{0} \mathrm{C}$. With the data from the same period of measurement is compared to each other, we can conduct a simple linear regression to develop a conversion function for generating a value of actual temperature from the acquired uncalibrated data of the thermocouple. The data generated from the conversion function will then be used as the realtime data used for control parameters and archives. Such is the data acquired during the calibration process.

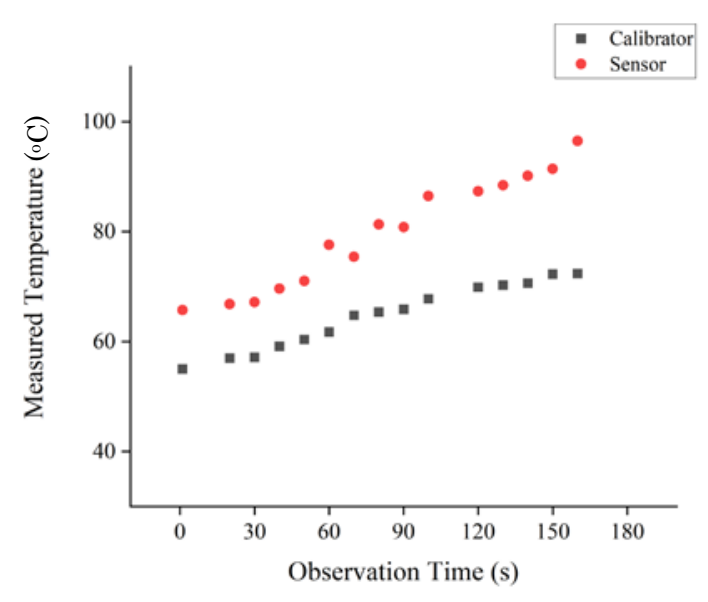

Fig. 3: Thermocouple calibration curve

From this data, statistic processes of linear regression can be done to generate the conversion function of:

$T_{\text {real }=} 1.261 T_{\text {coup }}-3.387$

This linear function, which consists of $\mathrm{T}_{\text {coup }}$ as a free variable is the value of temperature acquired by the thermocouple, and $T_{\text {real }}$ as a bound variable is the calibrated real value of the temperature which happens real-time. The generated linear function is accurate in its data range of 0 to $100{ }^{\circ} \mathrm{C}$.

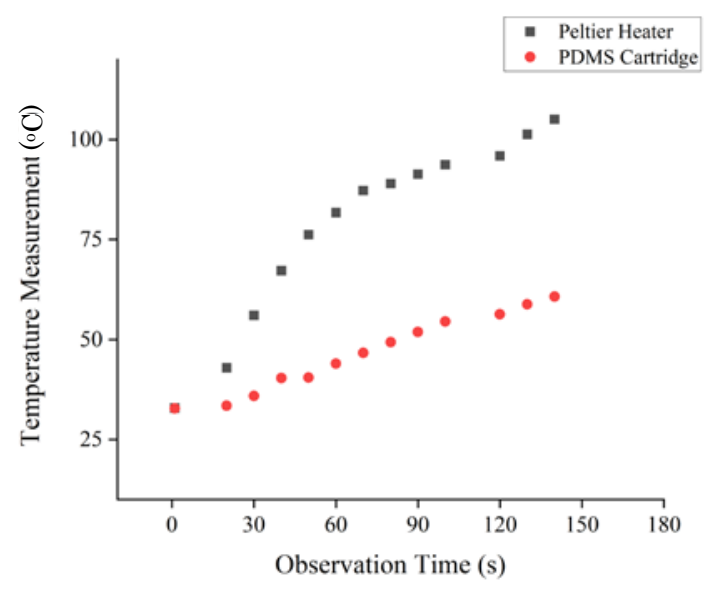

Fig. 4: Temperature of PDMS Cartridge and Peltier heater

As shown in Fig. 4, we can see there is quite a significant difference value of temperature between the PDMS LoC and Peltier element. The conduction equation shows that the conduction process interacts. The considerable temperature difference value can be taken to assume that PDMS as a material has a low amount of thermal conductivity, meaning prolonged heating is needed to heat the LoC to the target temperature. This supports the thermal cycler specification of $1.75 \pm 0.25{ }^{\circ} \mathrm{C}$ temperature ramp rate, were compared to the commercially available counterpart's ramp rate of averagely $3{ }^{\circ} \mathrm{C}$, it is relatively low. These characteristics 
will be used as a base to develop heating control logic.

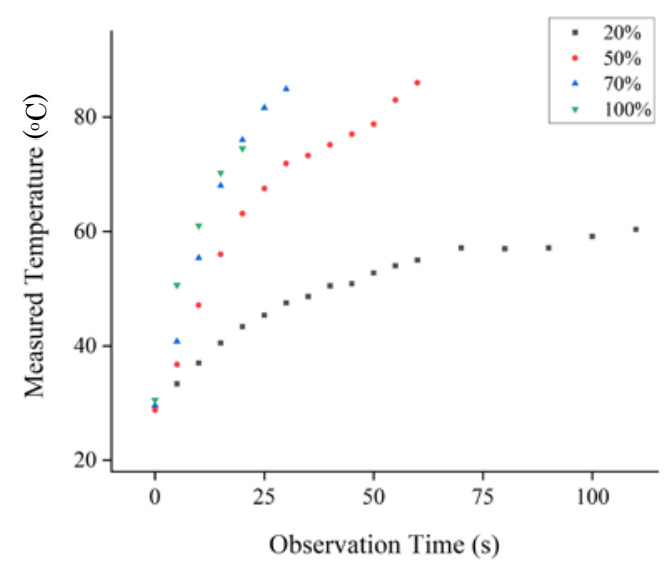

Fig. 5: Temperature over time during duty cycle test

A set of tests for the duty cycle was also performed to examine the performance of the thermal cycler. The duty cycle tests were performed under a different power input to the thermal cycler, ranging between 20 to $100 \%$. As depicted in Fig. 5, the results show that due to the thermoelectric effect of the Peltier element, the lower the input power, the longer it took for the thermal cycler to reach the desired temperature.

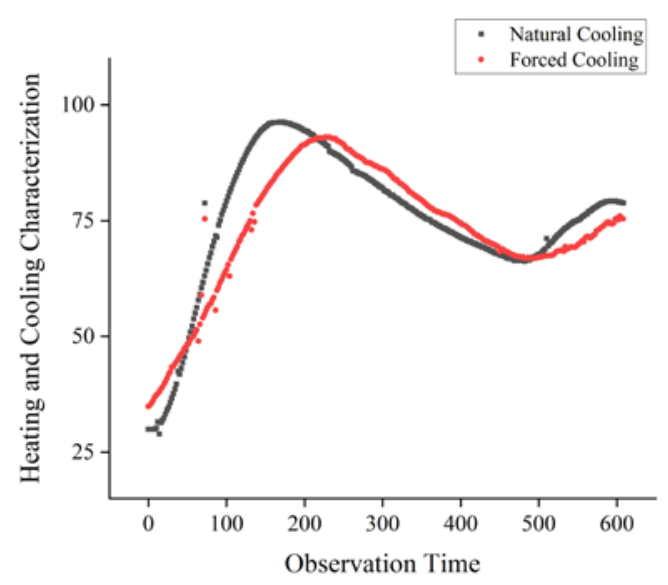

Fig. 6: Temperature of PDMS Cartridge under natural and forced cooling

Fig. 6 shows the temperature of PDMS cartridge under the variation of the cooling mode. The thermal cycler was tested with and without a fan. The test was done under one complete PCR cycle. Under the natural cooling mode, the thermal cycler was able to complete one PCR cycle in 764 seconds, whereas in forced cooling mode one complete PCR cycle was done in 573 seconds.

With the needed characteristics and calibration has been taken to account, the thermal cycler prototype can then be run to test its performance. The initial test is firstly done by setting the upper and lower control limit to be $\pm 1.5^{\circ} \mathrm{C}$ of the set temperatures. The set temperature value is continuously set at the value of $92{ }^{\circ} \mathrm{C}$ for denaturation, 65 ${ }^{\circ} \mathrm{C}$ for annealing, and $71{ }^{\circ} \mathrm{C}$ for elongation for trials to produce consistent results in its trial. Testing is done for 5 iterations in 3600 seconds (1 hour) duration under room temperature and atmospheric pressure to simulate usage under common free environment variables condition. With the temperature data is acquired and archived in realtime, we can find the cycle speed the prototype can also achieve the overshoot and undershoot that happens during usage. Such are the results presented in a scatter graph diagram.

From the scatter graph in Fig. 7, we got the value of PDMS temperature in real-time during the 1-hour trial duration. By putting the value of the temperature zones in mind, we can find the amount of cycle finished during the trial duration. It is found that by order of trials, the thermal cycler successfully runs the PCR processes for 7 cycles in $1^{\text {st }}$ cycles, 7 cycles in $2^{\text {nd }}$ trial, 6 cycles in $3^{\text {rd }}$ trial, 6 cycles in $4^{\text {th }}$ cycle, 7 cycles in $5^{\text {th }}$ trial, and with an average of 6.6 cycles and hour. From those data, we can find the value of the standard deviation of the thermal cycler performance which is 0.55 or $8.33 \%$ deviation based on its average value. This shows 2 major points of the thermal cycler prototype development, with firstly is that the PCR process heating control system is a successful design of control logic that can generate PCR process shown by how the data run successfully run multiple cycles consecutively and secondly, based on the value of standard deviation we can conclude there are still deviation and inconsistencies of performance results which means there is room for further control logic improvements.

From the data of the cycle amount, we can compare it to the value of the average cycle of 6.6 cycles using the six-sigma method to show further how reliable will the

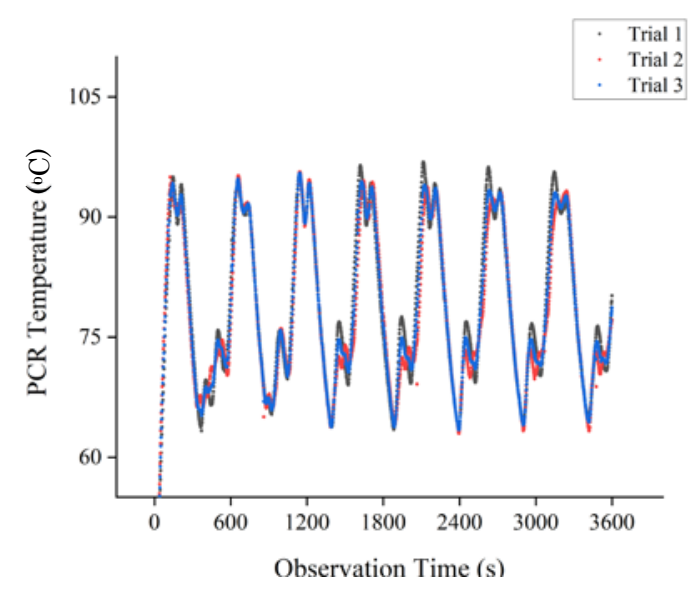

Fig. 7: Temperature of PDMS in thermal cycler performance test

thermal cycler works. The method shows that the process of the trial produces 1.7 sigma capabilities, which under percentage is that the process reliability falls in $40 \%$ chance of deviation and inconsistencies occur in its 
operations.

From the data collected, we can also find some overshoots and undershoots that frequently happen, especially overshoots during the denaturation process as it sets as the highest working set temperature. This fact coupled with the findings of inconsistent cycle speed performance results would further support the fact of how to control logic improvements have to be made.

\section{Conclusion}

A PDMS chip-based thermal cycler has been successfully realized through conventional methods and commercially available components. Despite the lessthan-ideal results of heat transfer analysis of the PDMS conduction phenomenon, the thermal cycler main parameters of heating control showed successful results through series of tests. The ability of the thermal cycler to reproduce identical results were presented during the performance test. The thermal cycler design is open to improvement to achieve portable DNA detection through modular integration.

\section{Acknowledgement}

This research was supported by the PUPT Kemristek in 2020 with Contract Number: NKB2872/UN2.RST/HKP.05.00/2020.

\section{References}

1) G. Wortmann, L.P. Hochberg, B.A. Arana, N.R. Rizzo, F. Arana, and J.R. Ryan, "Diagnosis of cutaneous leishmaniasis in guatemala using a real-time polymerase chain reaction assay and the smartcycler®,” Am. J. Trop. Med. Hyg., 76 (5) 906908 (2007).

2) S.J. Harper, L.I. Ward, and G.R.G. Clover, "Development of lamp and real-time pcr methods for the rapid detection of xylella fastidiosa for quarantine and field applications,” Phytopathology, 100 (12) 1282-1288 (2010).

3) J.Y. Takekawa, S.A. Iverson, A.K. Schultz, N.J. Hill, C.J. Cardona, W.M. Boyce, and J.P. Dudley, "Field detection of avian influenza virus in wild birds: evaluation of a portable rrt-pcr system and freezedried reagents," J. Virol. Methods, 166 (1-2) 92-97 (2010).

4) M.A. Abd Wahid, M.J.M.M. Noor, and H. Hara, "Recombinant moringa oleifera lectin produced in pichia pastoris is a potential natural coagulant," Evergreen, 03 (02) 11-16 (2016).

5) E.K. Wheeler, W. Benett, P. Stratton, J. Richards, A. Chen, A. Christian, K.D. Ness, J. Ortega, L.G. Li, T.H. Weisgraber, and others, "Convectively driven polymerase chain reaction thermal cycler," Anal. Chem., 76 (14) 4011-4016 (2004).

6) D. Wang, and J. Feng, "Simulation and Calculation of
Temperature in a Portable Real-Time PCR Instrument,” in: 2009 Int. Conf. Inf. Eng. Comput. Sci., 2009: pp. 1-4.

7) K.S. Chong, and K.B. Gan, "Portable polymerase chain reaction (PCR): thermal ramping rate performance evaluation,” in: 2016 IEEE EMBS Conf. Biomed. Eng. Sci., 2016: pp. 447-449.

8) H. Lim, G.E. Jo, K.S. Kim, S.M. Back, and H. Choi, "Miniaturized thermocycler based on thermoelectric heating for diagnosis of sexually transmitted disease by dna amplification," Rev. Sci. Instrum., 88 (5) 55001 (2017).

9) D. Pal, and V. Venkataraman, “A portable batteryoperated chip thermocycler based on induction heating," Sensors Actuators A Phys., 102 (1-2) 151156 (2002).

10) K.E. Herold, N. Sergeev, A. Matviyenko, and A. Rasooly, "Rapid DNA amplification using a batterypowered thin-film resistive thermocycler," in: Biosens. Biodetection, Springer, 2009: pp. 441-458.

11) J.M. Love, R. Marquis-Nicholson, R.C. Love, and D.R. Love, "Portable battery-operated rapid pcr amplification of the cag repeat region of the huntington disease locus,” Res. J. Biol., 2 (6) 191196 (2012).

12) T. Tsubota, A. Kitajou, and S. Okada, "O3-type na (fe_1/3mn_1/3co_1/3) o_2 as a cathode material with high rate and good charge-discharge cycle performance for sodium-ion batteries," Evergreen, 6 (4) 275-279 (2019).

13) S. Ramadhanty, M.H. Amirullah, M.H. Faturrahman, R. Dhelika, and T. Abuzairi, "Development of small scale electrohydrodynamic drying device for rough rice using dc plasma generator,” Evergreen, 6 (2) 103-107 (2019).

14) M. Mölsä, K.A. Koskela, E. Rönkkö, N. Ikonen, T. Ziegler, and S. Nikkari, "Detection of influenza a viruses with a portable real-time pcr instrument," $J$. Virol. Methods, 181 (2) 188-191 (2012).

15) L. Liu, Z. Benyeda, S. Zohari, A. Yacoub, M. Isaksson, M. Leijon, N. LeBlanc, J. Benyeda, and S. Belak, "Assessment of preparation of samples under the field conditions and a portable real-time rt-pcr assay for the rapid on-site detection of newcastle disease virus,” Transbound. Emerg. Dis., 63 (2) e245-e250 (2016).

16) L. Liu, Y. Luo, F. Accensi, L. Ganges, F. Rodriguez, H. Shan, K. Ståhl, H.-J. Qiu, and S. Belak, "Preclinical evaluation of a real-time pcr assay on a portable instrument as a possible field diagnostic tool: experiences from the testing of clinical samples for african and classical swine fever viruses," Transbound. Emerg. Dis., 64 (5) e31--e35 (2017).

17) E.L.A. Howson, B. Armson, N.A. Lyons, E. Chepkwony, C.J. Kasanga, S. Kandusi, N. Ndusilo, W. Yamazaki, D. Gizaw, S. Cleaveland, and others, "Direct detection and characterization of foot-and- 
mouth disease virus in east africa using a field-ready real-time pcr platform,” Transbound. Emerg. Dis., 65 (1) 221-231 (2018).

18) N.Z. Zaini, N.B. Kamaruzaman, and U. Abidin, "Magnetic microbeads trapping using microfluidic and permanent magnet system," Evergreen, 08 (01) 156-162 (2021).

19) C.D. Ahrberg, A. Manz, and B.G. Chung, "Polymerase chain reaction in microfluidic devices," Lab Chip, 16 (20) 3866-3884 (2016).

20) N.M. Zahra, R.C.P. Rampazzo, K.K. Leite, P.H.C. Schluga, M. Cereda, M. Bianchessi, L.G. Morello, M.A. Krieger, and A.D.T. Costa, "Advances to Bordetella pertussis diagnosis: Adapting a real time PCR to a lab-on-chip platform,” in: 2016 31st Symp. Microelectron. Technol. Devices, 2016: pp. 1-4.

21) Y. Whulanza, M.S. Utomo, and A. Hilman, "Realization of a passive micromixer using herringbone structure,” in: AIP Conf. Proc., 2018: p. 40003.

22) M. Phadke, S. Shaner, S. Shah, Y. Rodriguez, D. Wibowo, Y. Whulanza, P. Teriete, J. Allen, and S. Kassegne, "Inertial focusing and passive micromixing techniques for rare cells capturing microfluidic platform,” in: AIP Conf. Proc., AIP Publishing LLC , 2018: p. 040001. doi:10.1063/1.5023971.

23) Y. Whulanza, H. Nadhif, J. Istiyanto, S. Supriadi, and B. Bachtiar, "PDMS surface modification using biomachining method for biomedical application," $J$. Biomimetics, Biomater. Biomed. Eng., 26 66-72 (2016).

doi:10.4028/www.scientific.net/JBBBE.26.66.

24) J. Ranatan, R. Irwansyah, Warjito, and Y. Whulanza, "Testing of pneumatic actuation micro valve module for lab-on-a-chip application,” in: AIP Conf. Proc., 2020: p. 20011.

25) Y. Whulanza, T.A. Hakim, M.S. Utomo, R. Irwansyah, J. Charmet, and Warjito, "Design and characterization of finger-controlled micropump for lab-on-a-chip devices," Evergreen, $6 \quad$ (2) (2019). doi:10.5109/2321002.

26) T. Hsieh, C. Luo, G. Lee, C. Liao, and F. Huang, "A micromachined low-power-consumption portable pcr system,” J. Med. Biol. Eng., 26 (1) 43 (2006).

27) N.Y. Lee, and others, "A portable microreactor with minimal accessories for polymerase chain reaction: application to the determination of foodborne pathogens," Microchim. Acta, 184 (11) 4225-4233 (2017).

28) Y. Whulanza, R. Aditya, R. Arvialido, M.S. Utomo, and B.M. Bachtiar, "Ease fabrication of PCR modular chip for portable DNA detection kit," in: AIP Conf. Proc., AIP Publishing LLC , 2017: p. 040006. doi:10.1063/1.4976791. 